carnivores. Is the giant panda an overgrown, pied lesser panda or a bamboo-munching bear? There are essays on the lesser panda, and panda killers, and a thorough analysis of the features which make this rather dim-witted animal so appealing. The various appendices and a full bibliography make the book a valuable source of reference. It is a highly readable, often exciting work, illustrated and set out in a delightful way which more conservative publishers could do well to emulate. There is one serious omission, however, which the book itself may well help to fill; let us hope that a future edition may include a chapter on field work.

\title{
JOHN SPARKS
}

\section{Mammals of the Pacific States, by Lloyd C. Ingles. Stanford University Press and O.U.P., 80s.}

The first edition of this book was modestly confined to California; the second included the coastal waters and therefore a most interesting section on the whales; the third has reached farther afield to cover Oregon and Washington as well, so that the status of mammals in the important regions of the Cascades and the Olympic Peninsula is described. Though this work is so regional in its title and described as being for students and beginners in mammalogy, let no one be so mistaken as to pass it by lightly. It is a scholarly book of painstaking accuracy most serviceably illustrated. The valuable keys and descriptions are terse, as they should be, but the text is refreshingly interesting, so much so that many Old World students of mammals will be glad to have the book.

Anyone sensitive to the romance of the interlocked histories of men and other mammals will find several examples here. History is not all tragedy: Steller's sealion can still be seen by ordinary folk near San Francisco and at Monterey; and it is quite wonderful at that beautiful and thrilling Monterey Point to watch a sea otter lying on its back in the surf, after a period when we had thought it extinot. Further, there is the story of the grey whale, also thought to be extinct in American waters, which turned up again in Scammon's Bay, the place where that cunning old whaling captain had found it (and exploited it) a century ago. The gentle and playful behaviour of grey whale cows and their calves can be observed from the air, for the animals lie near the surface of the water.

Lloyd Ingles sees mammals in their total envinonment, physical and behavioural, and because of this deplores the training of students in depth before they have become educated in and aware of breadth. Members of this Society will so warmly agree with him.

\section{F. FRASER DARLING}

\section{The Terrestrial Mammals of Western Europe, by C. B. Corbet. Foulis, 56s.}

If national boundaries stand firm politically, they are, zoologically at least, now tending to vanish, especially as travel is so much easier to many parts of the world. Naturalists have been quick to take advantage of this and so there has been a need for a handbook such as this for a good many years. Up to date the only publication fulfilling the need has been the field guide by van den Brink, which has excellent illustrations but has not yet appeared in an English version.

But Dr Corbet's book, which covers European mammals west of Russia with the exception of bats, seals and whales, is a good deal more than a 
handbook for identification. One of its most welcome features is that it deals in a rational and up-to-date manner with the principles of taxonomy as applied to European mammals. Both professional and amateur mammalogists have felt for many years that their researches have had to be based on a taxonomy that was out of date. Dr Corbet, continuing the tradition of mammal research coming from the British Museum, now gives us a checklist of west European mammals, which incorporates conclusions from much recent, but scattered, taxonomic work. Much, obviously, remains to be done, but the nomenclature of European mammals, at least to the species level, can be regarded as having achieved some stability. Understandably, he gives only a skeleton bibliography, referring mainly to standard works and monographs.

Following the opening chapter on taxonomy is a short one on distribution which enunciates some interesting principles and processes. An excellent "potted" account follows of the structure of mammals which amateurs should not, and professionals will not, neglect. Then, after all too brief chapters on life-history and ecology (the latter, however, containing a valuable list of groups of animals parasitic upon mammals) the author launches on his systematic account which occupies two-thirds of the book.

By and large this part maintains an excellent evenness of approach throughout, giving a bird's-eye view of the mammal fauna of the area and of its inter-relationships without overloading the text with detail. There are keys to orders, families, genera and species and, where appropriate, these are repeated on external and on skull characters, though it should be noted that many of the external characters need the animal in the hand for determination. Distributions are described in the text, except where a few maps are provided (these are, however, almost diagrams, lacking lines of latitude and longitude and method of projection). The life-history is then given in varying degrees of fullness and, if a monograph has been published, it is cited. Particularly valuable are the paragraphs setting each family and genus against its world background.

The production is good, though the photographs are undistinguished. There are remarkably few mistakes, though the reviewer was delighted to find that the scops owl has been attributed to a hithento unknown ornithologist named Scop! In summary, there is no question that this book will deservedly find a wide audience.

\section{H. N. SOUTHERN}

\section{The Book of Australian Wildlife, by Harry Frauca. Heineman, $42 \mathrm{~s}$.}

The author is a professional collector and photographer of animals who appreciates the need to live in the bush to do his work properly, and the advantages of photographing anything of interest that comes his way, rather than making special trips in pursuit of particular species. He has learned to reject preconceived notions and to keep an open mind about animal behaviour. A self-taught naturalist, he sensibly seeks the advice of specialists and through his reading tries to keep abreast of current thinking.

His book consists of short chapters, dealing with Insects, Arachnids, Crabs, Frogs, Reptiles, Birds, Monotremes, Marsupials, placental mammals and introduced species. The text is a mixture of first-hand observations, the fruits of his reading, and some anecdotes; it is quite informative and pleasant general reading, although the style is uneven and sometimes 